\title{
SICKLE CELL DISEASE IN MALAWIAN CHILDREN IS ASSOCIATED WITH RESTRICTIVE SPIROMETRY: A CROSS SECTIONAL SURVEY
}

\author{
James Cook 1 , I , Olly Jefferis ${ }^{2, \S}$, Pacharo Matchere ${ }^{2,46}$, Emmie Mbale ${ }^{2,48}$, and Jamie \\ Rylance $^{3,4, \mathbb{I}}$ \\ ${ }^{1}$ Lewisham Hospital NHS Trust, London \\ ${ }^{2}$ Queen Elizabeth Central Hospital, Blantyre, Malawi \\ ${ }^{3}$ Malawi-Liverpool-Wellcome Clinical Research Programme, Blantyre, Malawi \\ ${ }^{4}$ Liverpool School of Tropical Medicine
}

\section{SUMMARY}

\begin{abstract}
Background-A proportion of children with sickle cell disease (SCD) demonstrate clinical findings consistent with the diagnosis of asthma. These children are at increased risk of complications including acute chest syndrome.
\end{abstract}

Objective-To assess lung function and symptoms of asthma in children with SCD in Blantyre, Malawi.

Design-Twenty-five children aged seven to sixteen with electrophoretically confirmed SCD were recruited to undergo spirometry and questionnaire screening of asthma symptoms. Forced expiratory volume in 1 second (FEV1), forced vital capacity (FVC) and $\mathrm{FEV}_{1} / \mathrm{FVC}$ ratio, were compared with local and international reference ranges. Symptoms were assessed using the International Study of Asthma and Allergies in Childhood questionnaire.

Results-Mean spirometric indices represented as z-scores derived from international reference ranges were low: $\mathrm{FEV}_{1}-1.64$ (95\% CI -2.04 to -1.23$)$, $\mathrm{FVC}-1.49$ (95\% CI -1.90 to -1.09 ), $\mathrm{FEV}_{1} / \mathrm{FVC}-0.39$ (95\% CI -0.76 to -0.03$)$. Comparison with local reference ranges, represented as percentage of predicted value, revealed similar impairments: $\mathrm{FEV}_{1} 86.9$ (95\% CI 81.1 to 92.7), FVC 89.0 (95\% CI 83.5 to 94.4 ), $\mathrm{FEV}_{1} / \mathrm{FVC}$ ratio 97.7 (95\% CI 95.4 to 99.9 ). The prevalence of wheeze was $16.7 \%$.

Conclusion-We present spirometric abnormalities suggestive of restrictive lung disease with no evidence of obstructive defects or increased prevalence of wheeze.

\section{Keywords}

paediatric; lung function; wheeze; asthma

\footnotetext{
Corresponding author: Dr James Cook, Kaleidoscope Centre for Children, Lewisham Hospital NHS Trust, London, SE13 6LH. Tel: (+44) 07793204553. Fax: (+44)02071381559 jamescook@doctors.org.uk.

Conception, design, acquisition of data, analysis and interpretation of data, drafting of article.

$\S_{\text {Conception and acquisition of data. }}$

${ }^{\text {HH}}$ Acquisition of data, questionnaire design.

Conflicts of Interest: None
} 


\section{INTRODUCTION}

A proportion of children with SCD exhibit clinical findings associated with the diagnosis of asthma, including wheeze, lower airway obstruction and bronchial hyper-reactivity. These clinical findings are more prevalent in children with SCD than in age and ethnically matched controls. ${ }^{1,2}$ It remains unclear whether these children are predisposed to develop asthma or if they are demonstrating a distinct pulmonary condition caused by SCD itself.

Characterizing the relationship between SCD in children and the clinical features of asthma is important. Lower airway obstruction ${ }^{3}$ and a physician diagnosis of asthma ${ }^{4}$ have been independently associated with increased rates of acute chest syndrome and vaso-occlusive crisis. Recurrent episodes of acute chest syndrome are the most important risk factor in the development of sickle chronic lung disease. ${ }^{5}$ This complication usually becomes apparent in early adulthood and is typified by restrictive pulmonary function, hypoxaemia ${ }^{6}$ and pulmonary hypertension. ${ }^{7}$ Both acute chest syndrome and sickle chronic lung disease are important causes of morbidity and mortality. ${ }^{8}$

The prevalence of SCD in Malawi is estimated at between one and three percent. ${ }^{9}{ }^{10} \mathrm{~A}$ proportion of Malawian children with SCD are likely to have undiagnosed clinical findings and symptoms consistent with asthma. These symptoms may be improved with the prescription of bronchodilators, which are locally available, although their effect on longterm outcomes such as rates of ACS has yet to be elucidated in randomized controlled trials. This study describes the pulmonary function of Malawian children with SCD and the prevalence of asthma symptoms within this cohort.

\section{METHODS}

\section{Study Population}

Children aged between seven and sixteen were recruited from the paediatric sickle cell clinic at Queen Elizabeth Central Hospital, Blantyre, between June and August 2011.

Homozygous sickle cell disease (HbSS) was confirmed by haemoglobin electrophoresis using a Beckman Paragon Electrophoresis System (Beckman Coulter Inc., California, USA).

Exclusion criteria were: clinic attendance within 1 month of a respiratory tract infection or HIV infection. The latter was to prevent confounding due to the negative impact of HIV on lung function. ${ }^{11}$ Screening for HIV infection was completed as per clinic protocol in all participants using a rapid antibody test (Determine, Inverness Medical).

\section{Pulmonary Function Testing}

Participants' height and weight were recorded on the day of spirometry using a wall fixed stadiometer and a SECA 761 electronic scale (SECA, Birmingham, UK). Spirometric testing followed ATS/ERS recommended practice ${ }^{12}$ using an EasyOne World spirometer (ndd AG, Zurich, Switzerland). Two clinicians independently interpreted the results, and assessed the quality and reproducibility of all trials. Traces not meeting quality and reproducibility criteria were excluded. Disparity in interpretation was resolved by consensus.

We measured forced expiratory volume in 1 second $\left(\mathrm{FEV}_{1}\right)$; forced vital capacity (FVC) and $\mathrm{FEV}_{1} / \mathrm{FVC}$ ratio. A primary comparison of these spirometric indices was made with reference values of Wang et al ${ }^{13}$ and were reported as $z$-scores $[z=(x-\mu) / \sigma$ where ' $x$ ' is the individual parameter and ' $\mu$ ' and ' $\sigma$ ' are mean and standard deviations of the reference range respectively]. The lower limit of normal (LLN) for $\mathrm{FEV}_{1}, \mathrm{FVC}$ and $\mathrm{FEV}_{1} / \mathrm{FVC}$ is defined as $\mathrm{z}<-1.64$ (below the 5 th centile). A second comparison was made with locally defined ranges from a recent cross-sectional survey in Blantyre, Malawi. ${ }^{14}$ In this case, 
where confidence intervals are not well defined, we report percentage of the predicted value, using $80 \%$ as the LLN.

The protocol determined that participants with an obstructive defect (defined by an $\mathrm{FEV}_{1} /$ FVC less than the lower limit of normal according to Wang et al ${ }^{13}$ ) would be given 200 micrograms of salbutamol (GlaxoSmithKline, Middlesex, UK) delivered via a metered dose inhaler and AeroChamber Plus spacer (Trudell Medical International, Ontario, Canada).

Response to bronchodilator would be assessed by repeat spirometry after fifteen minutes: an increase of $12 \%$ in $\mathrm{FEV}_{1}$ would be considered evidence of reversible lower airway obstruction. 15

\section{Questionnaire}

Symptoms of asthma were recorded in clinic using the International Study of Asthma and Allergies in Childhood (ISAAC) self-reporting questionnaire. This tool has a sensitivity of $85 \%$ and specificity of $81 \%$ when compared with a respiratory physician's diagnosis of asthma. ${ }^{16}$ Questions were translated into the national language (Chichewa) and, where required, a nurse assisted participants who had difficulty reading the questions. The results were compared with those of an ISAAC survey of Mozambican school children residing in urban areas. ${ }^{17}$ This survey population represents a proximal and demographically similar group that serves to give a useful estimate of symptoms of asthma in the Malawian paediatric population which is yet to be studied.

Additional information was sought to define the number of times participants had been admitted to hospital with chest pain and the prevalence of the use of solid fuel stoves for cooking in the home.

\section{Sample Size}

We calculated that 30 volunteers would be required to estimate the mean and standard deviation of FEV1 in our sample ${ }^{18}$, and allow comparison with the selected reference ranges. For a sample of 30 subjects there is a $20 \%$ chance that the sample standard deviation of FEV1 underestimates the population standard deviation by $22 \%$. The proportions of obstructive lung disease were unknown and inestimable a priori.

Statistical analysis was performed using Stata v11 (StataCorp, Texas, USA).

The Research and Ethics Committee of The University of Malawi College of Medicine granted ethical approval.

\section{RESULTS}

Twenty-five children (16 boys and 9 girls, median age 11.5 years, IQR 8 to 13.5) were recruited consecutively (Table 1). The target sample size was not attained due to the unexpected non-attendance of potential participants previously identified on a clinic list. All participants resided in urban areas within the district of Blantyre. The majority of participants ( $\mathrm{n}=20,83 \%)$ were exposed to products of biomass combustion for domestic cooking. Compared with World Health Organization growth charts ${ }^{19}$, participants were short (mean height for age $\mathrm{z}$-score $-1.21 \pm 0.90$ ), with five (20\%) defined as stunted (height for age z-score <-2). Participants were also below average weight (mean BMI for age zscore $-1.11 \pm 0.96)$ with four $(16 \%)$ defined as underweight (BMI for age $\mathrm{z}$-score $<-2$ ). Seven participants $(29 \%)$ reported a previous admission to hospital with chest pain and one participant reported over five previous admissions with chest pain. 
No participants were excluded due to recent symptoms of respiratory tract infection or HIV infection. One participant was excluded from the study because the spirometry traces obtained were un-interpretable. All other participants recorded good quality and reproducible traces. None of the traces recorded were consistent with an obstructive pattern and no participants were eligible for administration of inhaled salbutamol.

Primary comparison of pulmonary function was made with international reference ranges published by Wang et $\mathrm{al}^{13}$ (figure 1). The mean z-score for $\mathrm{FEV}_{1}$ was -1.64 (95\% CI -2.04 to -1.23$)$ and for FVC -1.49 (95\% CI -1.90 to -1.09$)$. Fifteen participants $(62 \%)$ had abnormally low $\mathrm{FEV}_{1}$, and fourteen participants (58\%) abnormally low FVC. The mean $\mathrm{FEV}_{1} / \mathrm{FVC} \mathrm{z}$-score was -0.39 (95\% CI -0.76 to -0.03$)$ and all values were within the normal range.

A second comparison of pulmonary function was made with reference ranges determined in a local cross-sectional survey ${ }^{14}$ (figure 2). Our cohort had a mean $\mathrm{FEV}_{1}$ of $86.9 \%$ of predicted (95\% CI 81.1 to 92.7 ) and mean FVC of $89.0 \%$ of predicted (95\% CI 83.5 to 94.4). Nine participants (37\%) had an abnormally low $\mathrm{FEV}_{1}$, while six (25\%) had an abnormally low FVC. The mean percentage of predicted $\mathrm{FEV}_{1} / \mathrm{FVC}$ value was 97.7 (95\% CI 95.4 to 99.9); no individual exhibited evidence of obstructive spirometry.

Predetermined explanatory variables predicted to be associated with $\mathrm{FEV}_{1}$ were entered into linear regression models for univariate analysis: none of these (age, BMI z-score, or number of admissions with chest pain) were significantly associated ( $>0.1$ for each).

Asthma symptoms recorded using an ISAAC questionnaire were compared with the results of an ISAAC survey of Mozambican school children conducted in $2006^{17}$ (Table 2). The prevalence of wheeze among the participants was lower than that recorded in Mozambican school children from urban areas. However the prevalence of nocturnal cough in the last 12 months was substantially higher among participants in this study $(41.7 \%$ v $22.7 \%)$.

\section{DISCUSSION}

\section{Main Findings}

In this small study in an area with low levels of asthma diagnosis, and low prevalence of wheeze, we have found no evidence to support the hypothesis of early acquisition of obstructive lung function defects in children with SCD. We have demonstrated lung function abnormalities suggestive of restrictive lung disease, and wheeze prevalence comparable to that of a cohort without SCD.

\section{Limitations}

As a cross sectional survey of a small number of patients we are reticent to draw wideranging conclusions. A larger patient population and cohort follow-up would allow more accurate determination of lung function including changes with age. It is possible that without testing for bronchial hyper-responsiveness we have missed both transient airway obstruction, and mixed obstructive/restrictive defects. Provocation testing is not available within our department, although questionnaire responses suggest low levels of asthma-type symptoms. The ISAAC questionnaire that we utilized was a translation of a standard questionnaire into the local language Chichewa. This was independent of the ISAAC study protocol, and the Chichewa translation was not formally validated. Further questionnaire analysis of risk factors for poor lung function might be illuminating, but our data was limited in order to maximize responses given the available resources. 


\section{Interpretation}

Malawian children with SCD may be progressing to the late stage lung changes found in SCLD more rapidly than previously studied paediatric populations who typically demonstrate obstructive rather than restrictive defects. ${ }^{1,2}$ If this is the case it may be that obstructive defects are present in younger children than those recruited in this study. The chronic pro-inflammatory state of the lungs in SCD has been shown in animal models to lead to increased sensitivity to hypoxic ${ }^{20}$, infectious ${ }^{21}$, and allergic ${ }^{22}$ insults. Repetition of these insults is thought to result in progressive fibrosis of the lung parenchyma and pulmonary vasculopathy; ultimately leading to the restrictive lung function and pulmonary hypertension associated with SCLD. ${ }^{7}$ It appears plausible that this cohort of patients has been exposed to a variety of location specific pulmonary insults, which may predispose to increased pulmonary inflammation and accelerated disease progression when compared with other groups. These insults may include; indoor air pollution from combustion of biomass fuels $^{23}$, high rates of pulmonary infection in the wider paediatric population ${ }^{24}$, inadequate nutrition $^{25}$, inefficient early identification of SCD affected individuals, and a lack of resources to treat the disease and its complications.

\section{Generalisability}

Our study highlights that the progression of the pulmonary complications associated with SCD may differ significantly between populations suggesting an important role of environmental influences. Further research might usefully examine these, and the extent to which the pattern of disease changes with the introduction of potential disease modifying therapies.

\section{Acknowledgments}

The authors would like to thank the participants and their family members for their time and enthusiasm.

Funding: None

\section{REFERENCES}

1. Ozbek OY, Malbora B, Sen N, Yazici AC, Ozyurek E, Ozbek N. Airway hyperreactivity detected by methacholine challenge in children with sickle cell disease. Pediatr Pulmonol. 2007; 42(12): 1187-1192. [PubMed: 17960821]

2. Knight-Madden JM, Forrester TS, Lewis NA, Greenough A. Asthma in children with sickle cell disease and its association with acute chest syndrome. Thorax. 2005; 60(3):206-210. [PubMed: 15741436]

3. Boyd JH, DeBaun MR, Morgan WJ, Mao J, Strunk RC. Lower airway obstruction is associated with increased morbidity in children with sickle cell disease. Pediatr Pulmonol. 2009; 44(3):290-296. [PubMed: 19205057]

4. Boyd JH, Macklin EA, Strunk RC, DeBaun MR. Asthma is associated with increased mortality in individuals with sickle cell anemia. Haematologica. 2007; 92(8):1115-1118. [PubMed: 17650441]

5. Knight-Madden JM, Forrester TS, Lewis NA, Greenough A. The impact of recurrent acute chest syndrome on the lung function of young adults with sickle cell disease. Lung. 2010; 188(6):499504. [PubMed: 20644948]

6. Powars D, Weidman JA, Odom-Maryon T, Niland JC, Johnson C. Sickle cell chronic lung disease: prior morbidity and the risk of pulmonary failure. Medicine. 1988; 67(1):66-76. [PubMed: 3336282]

7. Machado RF, Gladwin MT. Chronic sickle cell lung disease: new insights into the diagnosis, pathogenesis and treatment of pulmonary hypertension. Br J Haematol. 2005; 129(4):449-464. [PubMed: 15877728] 
8. Platt OS, Brambilla DJ, Rosse WF, et al. Mortality in sickle cell disease. Life expectancy and risk factors for early death. N Engl J Med. 1994; 330(23):1639-1644. [PubMed: 7993409]

9. Calis JC, Phiri KS, Faragher EB, et al. Severe anemia in Malawian children. N Engl J Med. 2008; 358(9):888-899. [PubMed: 18305266]

10. Brabin BJ, Prinsen-Geerligs PD, Verhoeff FH, et al. Haematological profiles of the people of rural southern Malawi: an overview. Ann Trop Med Parasitol. 2004; 98(1):71-83. [PubMed: 15000734]

11. Ferrand RA, Desai SR, Hopkins C, et al. Chronic lung disease in adolescents with delayed diagnosis of vertically-acquired HIV infection. Clin Infect Dis. In press.

12. Pellegrino R, Viegi G, Brusasco V, et al. Interpretative strategies for lung function tests. European Respir J. 2005; 26(5):948-968. [PubMed: 16264058]

13. Wang X, Dockery DW, Wypij D, Fay ME, Ferris BG. Pulmonary function between 6 and 18 years of age. Pediatr Pulmonol. 1993; 15(2):75-88. [PubMed: 8474788]

14. Zverev Y, Gondwe M. Ventilatory capacity indices in Malawian children. East Afr Med J. 2001; 78(1):14-18. [PubMed: 11320757]

15. Crapo RO, Casaburi R, Coates AL, et al. Guidelines for methacholine and exercise challenge testing-1999. Am J Respir Crit Care Med. 2000; 161(1):309-329. [PubMed: 10619836]

16. Jenkins MA, Clarke JR, Carlin JB, et al. Validation of questionnaire and bronchial hyperresponsiveness against respiratory physician assessment in the diagnosis of asthma. Int $\mathbf{J}$ Epidemiol. 1996; 25(3):609-616. [PubMed: 8671563]

17. Mavale-Manuel S, Joaquim O, Nunes E, et al. Prevalence of asthma-like symptoms by ISAAC video questionnaire in Mozambican schoolchildren. Monaldi Arch Chest Dis. 2006; 65(4):189195. [PubMed: 17393663]

18. Lancaster GA, Dodd S, Williamson PR. Design and analysis of pilot studies: recommendations for good practice. J Eval Clin Pract. 2004; 10:307-312. [PubMed: 15189396]

19. Growth reference data for children and adolescents, 5-19 years. World Health Organization; 2007. www.who.int/growthref/en/ [accessed 23/09/2011]

20. Kaul DK, Hebbel RP. Hypoxia/reoxygenation causes inflammatory response in transgenic sickle mice but not in normal mice. J Clin Invest. 2000; 106:411-420. [PubMed: 10930444]

21. Holtzclaw JD, Jack D, Aguayo SM, Eckman JR, Roman J, Hsu LL. Enhanced Pulmonary and Systemic Response to Endotoxin in Transgenic Sickle Mice. Am J Respir Crit Care Med. 2004; 169:687-695. [PubMed: 14684557]

22. Nandedkar SD, Feroah TR, Hutchins W, et al. Histopathology of experimentally induced asthma in a murine model of sickle cell disease. Blood. 2008; 112:2529-2538. [PubMed: 18579795]

23. Ong T, Mehta A, Ogston S, Mukhopadhyay S. Prediciton of lung function in the inadequately nourished. Arch Dis Child. 1998; 79:18-21. [PubMed: 9771246]

24. Torres-Duque C, Maldonado D, Perez-Padilla R, Ezzati M, Viegi G. Biomass fuels and respiratory diseases a review of the evidence. Proc Am Thorac Soc. 2008; 5:577-590. [PubMed: 18625750]

25. Ruden I, Boschi-Pinto C, Biloglav Z, Mulholland K, Campbell H. Epidemiology and etiology of childhood pneumonia. Bull World Health Organ. 2008; 86:408-416B. [PubMed: 18545744] 


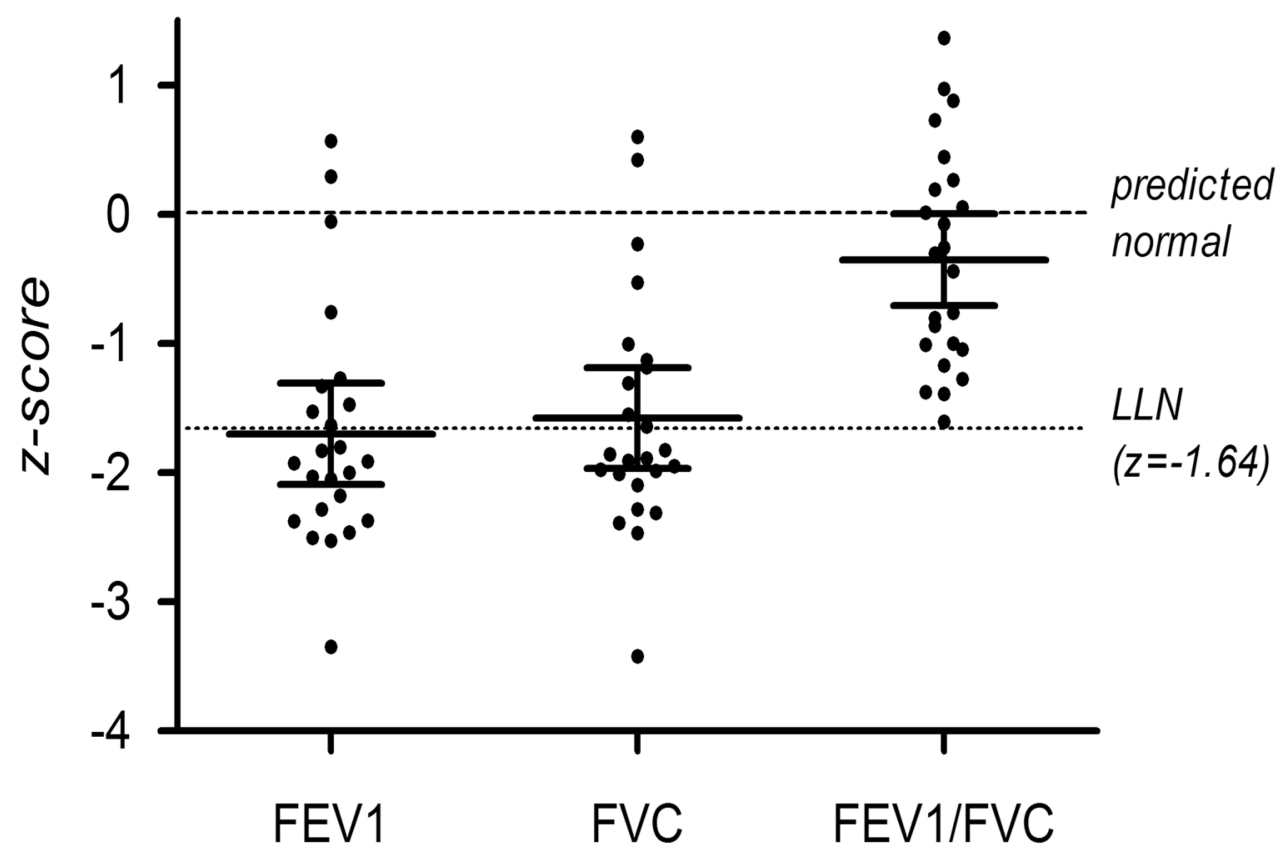

Figure 1.

Comparison of lung function with reference ranges published by Wang et al. ${ }^{13}$ Values of participants are given as z-scores where -1.64 is defined as the lower limit of normal. Error bars represent the $95 \%$ confidence interval around the mean. 


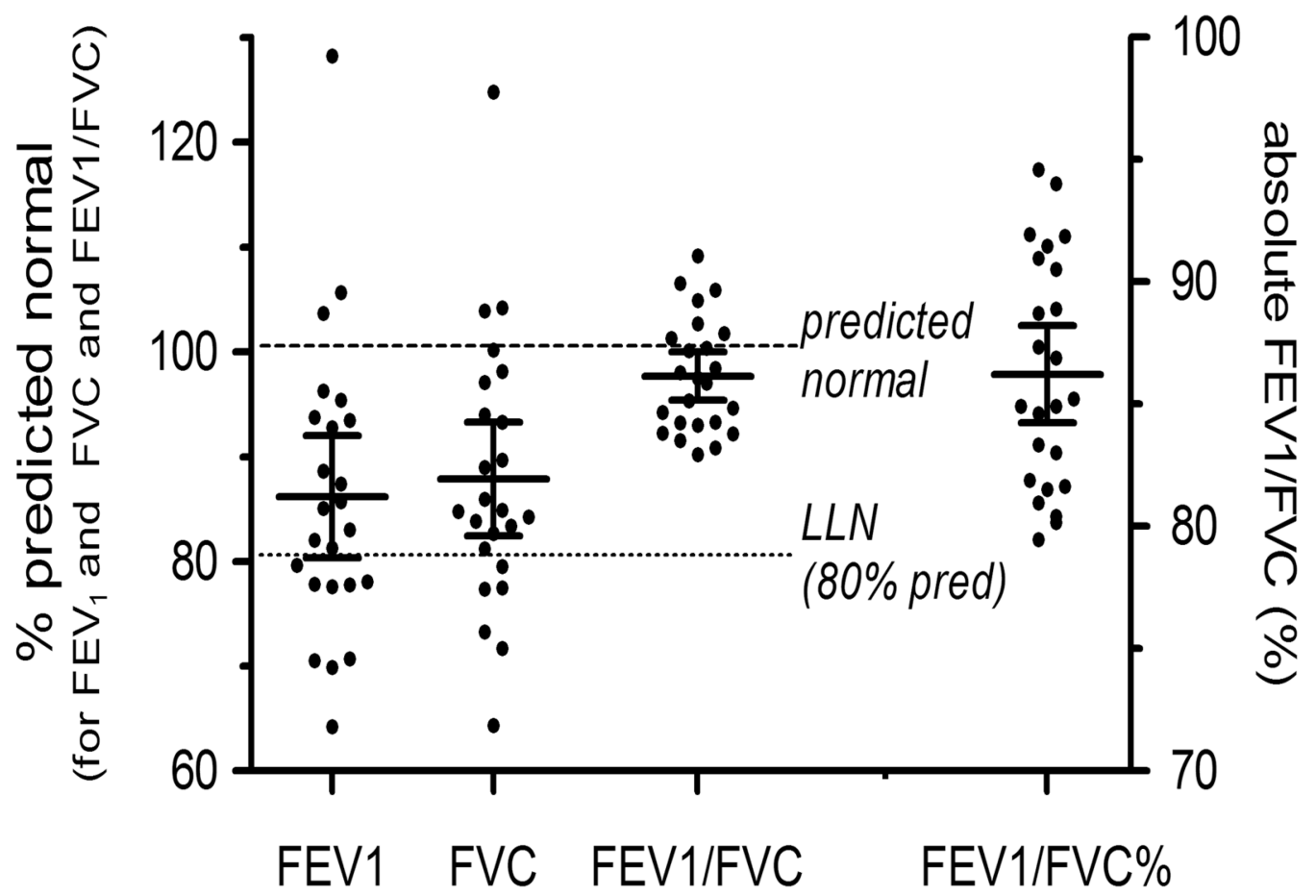

Figure 2.

Comparison of lung function with locally defined reference ranges published by Zverev et al. ${ }^{14}$ Values of participants are given as a percentage of predicted value with $80 \%$ defined as the lower limit of normal. Error bars represent the $95 \%$ confidence intervals around the mean. $\mathrm{FEV}_{1} / \mathrm{FVC}$ ratios are also given as absolute values. 
Table 1

Characteristics of study subjects

\begin{tabular}{|l|l|}
\hline Age, years & $11.2 \pm 3.09$ \\
\hline Female sex, $n(\%)$ & $8(33)$ \\
\hline Height, $c m$ & $136.4 \pm 15.1$ \\
\hline Height for Age, $z$-score & $-1.21 \pm 0.90$ \\
\hline Weight, $k g$ & $30.1 \pm 9.48$ \\
\hline BMI for Age, $z$-score & $-1.11 \pm 0.96$ \\
\hline Admissions with chest pain, $n(\%)$ & $7(29)$ \\
\hline Solid fuel stove, $n(\%)$ & $20(83)$ \\
\hline $\mathrm{FEV}_{1}, L / s$ & $1.45 \pm 0.54$ \\
\hline $\mathrm{FVC}, L$ & $1.68 \pm 0.58$ \\
\hline $\mathrm{FEV}_{1} / \mathrm{FVC} \%$ & $86 \pm 5.09$ \\
\hline
\end{tabular}

Plus-minus values are mean $\pm \mathrm{SD}$ 
Table 2

ISAAC questionnaire results and comparison with results of a survey of Mozambican school children. ${ }^{18}$

\begin{tabular}{|l|c|c|}
\hline & $\begin{array}{c}\text { Study } \\
\text { participants } \\
\boldsymbol{n}(\boldsymbol{\%})\end{array}$ & $\begin{array}{c}\text { Mozambican } \\
\text { children }^{\mathbf{1 8}} \\
\mathbf{\%}\end{array}$ \\
\hline Wheeze at any time in past & $4(16.7)$ & 20.3 \\
\hline Wheeze in last 12 months & $1(4.2)$ & 11.2 \\
\hline Wheeze after exercise in last 12 months & $4(16.7)$ & 24.6 \\
\hline Cough at night in last 12 months & $10(41.7)$ & 22.7 \\
\hline
\end{tabular}

